\title{
Algae-derived hard carbon anodes for $\mathrm{Na}$-ion batteries
}

\author{
Eugenio Gibertini ${ }^{1} \cdot$ Francesco Liberale $^{1} \cdot$ Carlo Dossi $^{2} \cdot$ Gilberto Binda $^{2} \cdot$ Barbara Mattioli $^{2} \cdot$ Roberta Bettinetti $^{3}$. \\ Angelo Maspero ${ }^{4} \cdot$ Michele Fiore $^{5} \cdot$ Riccardo Ruffo $^{5} \cdot$ Luca Magagnin $^{1}(\mathbb{B}$
}

Received: 27 February 2021 / Accepted: 18 July 2021 / Published online: 30 July 2021

(c) The Author(s) 2021

\begin{abstract}
In this work, the production of low cost and environment friendly anodes for sodium ion batteries is investigated. Algae are selected as bio-source of non-graphitic Hard Carbon (HC) with open structure acting as intercalation active material for $\mathrm{Na}$ ions storage. Chlorella vulgaris algae were pyrolyzed at temperatures comprised between 800 and $1100{ }^{\circ} \mathrm{C}$. The decomposition products have been characterized with Scanning Electrode Microscope (SEM) and X-Ray Diffraction (XRD) analyses and their structure compared to one of the synthetic commercial HC. Thermogravimetric analysis (TGA) allowed to assess the decomposition process throughout the selected temperature scan. The obtained algae-derived HC is tested as anodic material for Na-ion battery, investigating the effect of pyrolysis temperature on the electrochemical behaviour. Their performances are compared with respect to a commercial synthetic $\mathrm{HC}$ active material. The results allow to consider algae as an environmentally benign and sustainable high added-value material for the production of HC anodes for Na-ion batteries.
\end{abstract}

\section{Graphic abstract}

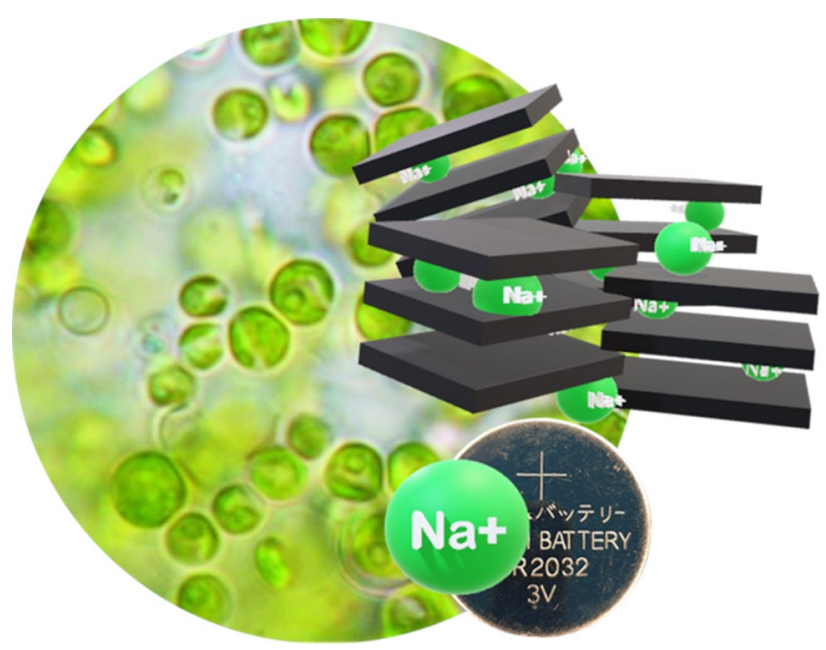

Keywords Algae $\cdot$ Hard Carbon $\cdot$ Na-ion battery $\cdot$ Pyrolysis

This article belongs to the Topical Collection: Batteries.

Luca Magagnin

luca.magagnin@polimi.it

1 Dipartimento di Chimica, Materiali e Ingegneria Chimica Giulio Natta, Politecnico di Milano, Via Mancinelli, 7, 20131 Milano, Italy

2 Dipartimento di Scienze Teoriche e Applicate, Università degli Studi dell'Insubria, Via Dunant 3, 21100 Varese, Italy
3 Dipartimento di Scienze Umane e dell'Innovazione per il Territorio, Università degli Studi dell'Insubria, Via Valleggio 11, 22100 Como, Italy

4 Dipartimento di Scienza e Alta Tecnologia, Università degli Studi dell'Insubria, Via Valleggio, 9 - 22100 Como, Italy

5 Dipartimento di Scienza dei Materiali, Università degli Studi di Milano-Bicocca, Via Cozzi 55, 20125 Milano, Italy 


\section{Introduction}

Energy crisis and environmental pollution are two of the main global issues we will have to face more directly in the next future. Constant rise in the population growth, especially in developing countries, exacerbates this issue and points out the need for a more accurate and focussed exploitation and management of renewable sources. In this approach, the storage and conversion of green sources will play a key and strategic role in the energy policies of both countries and companies. The development of new rechargeable batteries has shown a constantly increasing impulse in the last years, with the twofold aims of (a) improving the electrochemical performances of energy storage systems and (b) offering an environmentally friendly and efficient alternative to fossil fuels in the transport industry [1]. Lithium based batteries have been represented and still represent an essential technological and commercial success. However, the uneven distribution of lithium supplies and their progressive depletion over the years are a key concern to the future developments of materials and technologies for its recovery and recycle from spent batteries.

Sodium, the fourth most abundant element on the Earth's crust, with a distribution that is almost infinite and more uniform than lithium, is a viable candidate for its wide use in rechargeable batteries [2]. The study of sodium ion batteries is certainly not recent, beginning in parallel with that of lithium in the seventies, but it was partially abandoned thanks to the faster development and commercial success of the latter. One of its main drawbacks, which limited the diffusion of sodium technology, is the impossibility of using graphite as active material due to the bigger dimensions of sodium ions compared to lithium ones, together with the wider electrode's active material expansion during cycling. Some non-carbonaceous materials may be used as anodes such as phosphorus and phosphides [3], Sn oxides and sulphides [4, 5], and MXenes [6], but Hard Carbon (HC) is still considered the conventional choice in replacement of graphite to accommodate sodium ions at low potential $[2,7]$. HC, with its peculiar structure formed by randomly stacked graphene layers linked by crosslinking molecules, nanopores and defects can host considerable amount of sodium. Its structure can be described by the so-called "falling card model" [8]. HC commercially available is conventionally obtained by petroleum coke and synthetic derivates. However, the abundance of biomasses, together with their great availability and low costs, made them attractive to use these materials as carbonaceous precursors for electrodes active materials. HC obtained from a biomass precursor can be produced through a simple pyrolysis and the carbon structure can be conveniently tuned according to process parameters, with carbonization degree, surface morphology, and specific surface area as main factors governing the final electrochemical behaviour [9, 10]. Moreover, recent studies have demonstrated that heteroatoms as nitrogen, phosphorous, and magnesium in the biomass precursors lead to $\mathrm{HC}$ with improved performances as Na-ion battery's negative electrode [11-14]. Different kinds of biomasses were investigated as source for high-performance $\mathrm{HCs}$ for Na-ion batteries, due to the intrinsic selfdoping of the $\mathrm{HC}$ obtained after pyrolysis derived from the chemical composition of the feedstocks. Some examples of feedstocks used for Na-ion batteries include sugar [15] and various plants, peels and shells [9] such as apple wastes [16], banana peel [17], peanut shell [18], and different other biowaste sources $[19,20]$ demonstrating better performances with respect to standard synthetic HCs.

More recently, the exploitation of algae as precursors for $\mathrm{HC}$ attracted particular interest [21, 22], since these biomass feedstocks present fast growth rate, high carbon fixing efficiency, and can be harvested in polluted water. Moreover, naturally blooming algae are often removed from water bodies as waste, because of the well-known issue of eutrophication of fresh and sea water due to the excess concentration of phytostimulant substances commonly used as fertilizing agents, in particular, phosphorus- and nitrogen-containing chemicals. Herein, the possibility of using a common and widely spread algae, Chlorella vulgaris, as source for the synthesis of organic-derived $\mathrm{HC}$ as negative electrode in Na-ion batteries is demonstrated. The electrochemical performances of the electrodes obtained with the optimized decomposition conditions and process formulation are comparable with those produced with commercial, syntheticderived material.

\section{Experimental}

\subsection{Algal growth}

Chlorella vulgaris algae were grown in a low-mineral-content fresh water. In order to continuously feed the growing algae with the correct supply of nutritive substances, the water was enriched with a proper content of salts. A defined quantity of initial algal biomass (inoculum) is afterwards added to the salty water solution and then the culture is exposed to light. The exact amount is defined following the "OECD guidelines for the testing of chemicals", and it corresponds to $4-5^{*} 10^{3}$ cell $\mathrm{ml}^{-1}$ for both the species. The uncontaminated solution is kept under stirring and constantly exposed to light to promote the growth. During the growth process, algae were counted with a Burker counting chamber. Values of the growth rate were obtained relating 
the number of algal cells with the time in agreement with the standard UNI EN ISO 8692:2005.

\subsection{Algae pyrolysis}

Algae were dried at $100{ }^{\circ} \mathrm{C}$ in oven overnight to remove moisture. Pyrolysis was performed through sequential thermal ramps in tubular furnace, under inert nitrogen atmosphere, up to final temperatures comprised between 850 and $1100{ }^{\circ} \mathrm{C}$, maintaining it for $1 \mathrm{~h}$ and then cooling down naturally. A black powder was then obtained and named AHC850 and $\mathrm{AHC} 1100$ according to the pyrolysis temperature.

\subsection{Materials characterization}

The amount of carbon, hydrogen, and nitrogen in the organic sample grown algae was measured with elemental $\mathrm{CHN}$ analysis executed on a Perkin-Elmer CHN Analyzer Series II 2400. Briefly, about $5 \mathrm{mg}$ of algal biomass are weighted and then heated in crucibles at $900{ }^{\circ} \mathrm{C}$ for $2-6 \mathrm{~min}$ in an oxygen atmosphere, where an oxidative combustion is promoted, thus producing a mixture of $\mathrm{CO}, \mathrm{H}_{2} \mathrm{O}, \mathrm{N}_{2}$ and $\mathrm{NO} x$. The gas then passes through a Copper tube at $750{ }^{\circ} \mathrm{C}$, where $\mathrm{NO} x$ is reduced to $\mathrm{N}_{2}$ and $\mathrm{CO}$ is oxidized by copper oxide to give $\mathrm{CO}_{2}$. By analysing the percentage of $\mathrm{C}, \mathrm{H}$ and $\mathrm{N}$, it is possible to determine the lipid, protein and carbohydrates content. Thermogravimetric analyses (TGA) were performed with a NETZSCH STA 409 PC LUXX simultaneous thermal analyzer to determine the moisture, ash, volatile matter and residual carbon content. The samples were heated at $10{ }^{\circ} \mathrm{C} / \mathrm{min}$ ramp in the range $25-850{ }^{\circ} \mathrm{C}$ under inert $\mathrm{N} 2$ atmosphere. The data were compared with those obtained with a different thermal ramp, with two constant $\mathrm{T}$ regions for $1 \mathrm{~h}$ at 350 and $850{ }^{\circ} \mathrm{C}$, respectively. Morphology of pyrolyzed products and elemental analyses were carried out through scanning electron microscopy (SEM) (Zeiss EVO $50 \mathrm{EP}$ ) equipped with energy dispersive spectroscope (EDS) (Oxford instruments INCA $x$-sight detector). Microstructural investigation was performed by X-ray diffraction (XRD) (Philips model PW1830. K $\alpha 1 \mathrm{Cu}=1.54058 \AA$ A).

\subsection{Electrochemical characterization}

The slurry for the casting process was prepared according to the following procedure. PVDF binder (Solef 6020, SOLVAY) was dissolved in $N$-Methyl-2-pyrrolidone (SigmaAldrich) by overnight stirring. Afterwards, the pyrolyzed algae powder was mixed with carbon black (VULCAN $\mathrm{XC}-72, \mathrm{CABOT}$ ) and the two powders added to the dissolved PVDF. The relative ratio between the three components Algae:PVDF:CB was of 8:1:1. The obtained slurry was coated with a wet thickness of $100 \mu \mathrm{m}$ on a copper foil using ELCOMETER 4340 film applicator and electrodes were dried in vacuum oven at $120{ }^{\circ} \mathrm{C}$ overnight. The half coin cells (CR2032) were assembled in argon-filled glove box (MBraun LABstar) using metallic sodium as counter electrode, $1 \mathrm{M}$ sodium perchlorate (Sigma-Aldrich) in a 1:1 volume ratio mixture of ethylene carbonate (EC), and diethyl carbonate (DEC) (Sigma-Aldrich) as electrolyte. To set an experimental benchmark, a synthetic HC (SHC) (CARBOTRON P, KUREHA CORPORATION) was used as active material.

\section{Results and discussion}

Chlorella vulgaris is a unicellular fresh water algal species, with spherical shape of average dimension between 5 and $10 \mu \mathrm{m}$. Its high lipidic content (over 40\%) makes it attractive also in the development of biofuels and, as overall, an ideal candidate for an almost zero-waste by-product process. CHN analysis of Chlorella vulgaris revealed a carbon, hydrogen and nitrogen atomic content of $48.6 \%, 7.9 \%$ and $7.2 \%$, respectively [23]. This biomass presents almost a tenfold concentration of nitrogen compared to the typical concentration of lignocellulosic biomasses, but similar concentration in carbon and hydrogen. Precursor carbonization process is a critical step with a twofold aim: maximize yields of final solid residue for the potential industrial competivity of $\mathrm{HC}$ obtained by biomass pyrolysis and provide a carbon residue with enhanced or comparable electrochemical performances with respect to the conventional $\mathrm{HC}$ material. As a consequence, the effect of thermal ramps on the pyrolysis process was investigated up to $850{ }^{\circ} \mathrm{C}$, because at higher temperature, structure rearrangements take place instead of pyrolysis. TGA, DTG, and DSC curves of the Chlorella vulgaris seaweed are reported in Fig. 1a for the single-step thermal ramp. The continuous weight loss, occurring up to $150{ }^{\circ} \mathrm{C}$ and counted to $8.30 \%$, was related to moisture and non-bonded water release, as typical for hygroscopic materials. The DSC data confirmed this behaviour, presenting an endothermal peak in the same temperature interval. The second weight loss occurs at various extent in a broad range of temperatures starting from 350 to $800{ }^{\circ} \mathrm{C}$. In this region, decomposition of proteins, lipids and carbohydrates overlaps [24]. According to other studies and coherently with our results, fragmentation of hydrocarbon chains of fatty acids occurred up to $\sim 400{ }^{\circ} \mathrm{C}$, corresponding with the peak in mass loss around $330^{\circ} \mathrm{C}$. DSC coherently confirms a spontaneous thermal degradation process, with an exothermic peak following the $330{ }^{\circ} \mathrm{C}$ DTG one. Further, slower mass loss above $500^{\circ} \mathrm{C}$ was probably related to partial decomposition of carbonaceous residue. The final solid char at $850^{\circ} \mathrm{C}$ was $24.20 \%$.

As reported in other studies, a viscous liquid condensed in the cold part of the phial from $350{ }^{\circ} \mathrm{C}$, due to the partial 

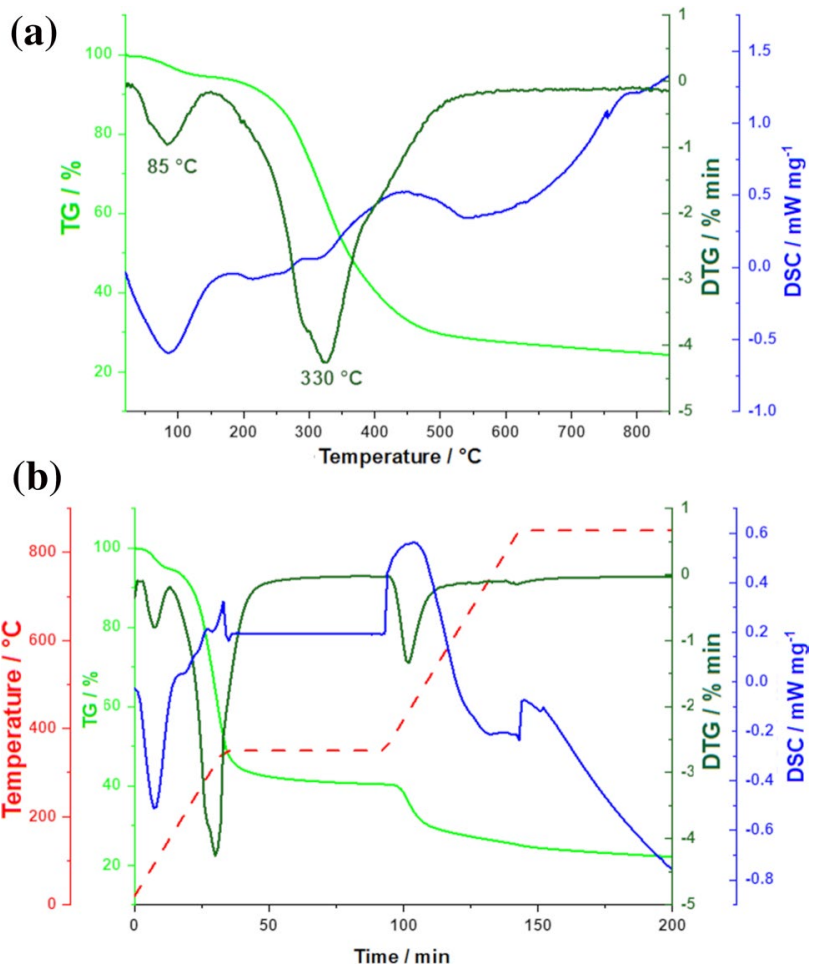

Fig. 1 TGA and DSC analyses on Chlorella vulgaris with a singlestep thermal ramp (a) and 4-step thermal ramp (b) together with the thermal profile (b)

thermal degradation of lipids producing fatty acid esters and hydrocarbons $[25,26]$. A complete decomposition of longchain lipids is instead required to simultaneously extract useful precursor for bio-oils and to enhance yield of final carbon residue. As consequence, Chlorella vulgaris was then pyrolyzed by adding two stasis times for $1 \mathrm{~h}$ at $350{ }^{\circ} \mathrm{C}$ and $850^{\circ} \mathrm{C}$. The thermal profile is reported in Fig. $1 \mathrm{~b}$, together with related TGA, DTG, and DSC profile. As clear from the TGA curve, a $15 \%$ weight loss occurred during the stasis at $350{ }^{\circ} \mathrm{C}$, allowing a much slower mass loss and exothermicity compared to the previous case as evidenced by DTG and DSC profile. Moreover, the last stasis at $850{ }^{\circ} \mathrm{C}$ resulted in further $3 \%$ mass loss, producing a better quality of final char residue, likely going along with structural rearrangement as suggested by endothermic trend of DSC [27]. It is noteworthy that the final yield of carbon residue was similar with the two different carbonization profiles. However, the two-step profile may be advantageous in terms of cleanliness and morphological homogeneity of the hard carbon, as well as for the possibility of recovering a high amount of bio-oil products with a potential use as energy source. SEM images of the algae precursor and carbonaceous residue of pyrolysis carried out at 850 and $1100{ }^{\circ} \mathrm{C}$ are reported in Fig. 2. In Fig. 2a, the peculiar shape of Chlorella vulgaris is visible as spherical particles of few tens of $\mu \mathrm{m}$ size. After pyrolysis, the spheroidal shape was replaced by smaller nonuniform agglomerates with highly corrugated surfaces for both AHC 850 and AHC1100, as shown in Fig. 2b and c, respectively.

EDS analysis performed on AHC1100 disclosed the presence of significant quantities of $\mathrm{Mg}$ and $\mathrm{P}$. These heteroatoms are abundant in Chlorella vulgaris and present in final carbon residue as minor secondary phases. XRD analyses on pyrolyzed products were compared with respect to the SHC taken as benchmark material, and the relative patterns are reported in Fig. 2d. SHC showed the
Fig. 2 SEM images of dried algae before pyrolysis (a) and after pyrolysis process at $850{ }^{\circ} \mathrm{C}$ (b) and $1100{ }^{\circ} \mathrm{C}(\mathbf{c})$. Scale bars are $10 \mu \mathrm{m}$ for (a) and (b) and $5 \mu \mathrm{m}$ for (c). The EDS spectrum relative to the $1100{ }^{\circ} \mathrm{C}$ pyrolyzed algae is reported in the inset of (c). XRD patterns for SHC, AHC850 and AHC1100 powders (d) (a)

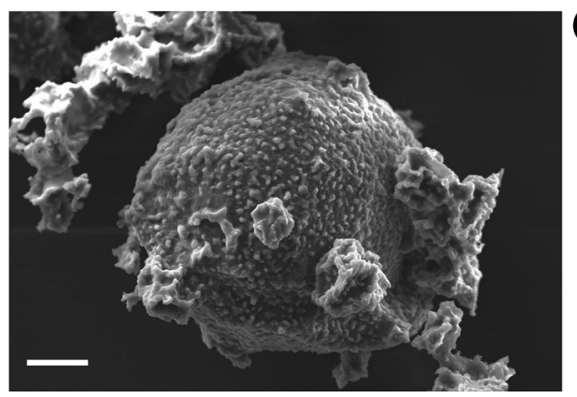

(c)

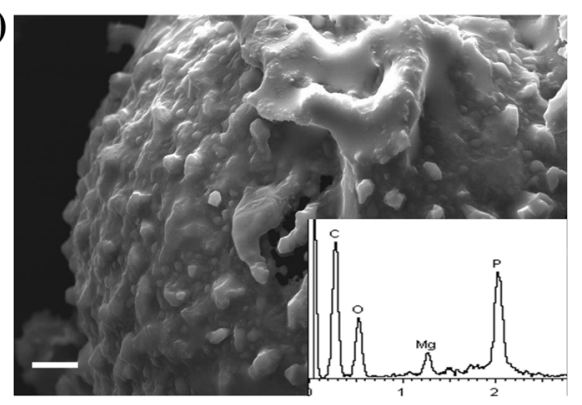

(b)

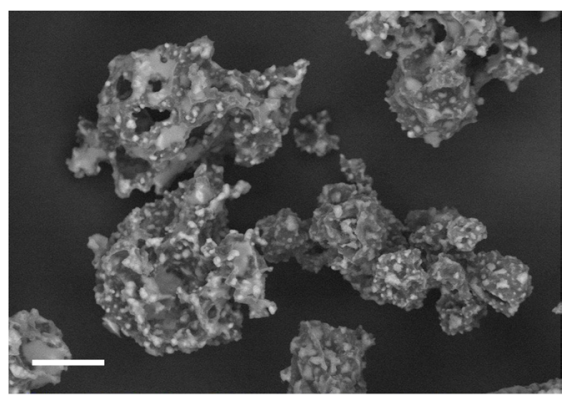

(d)

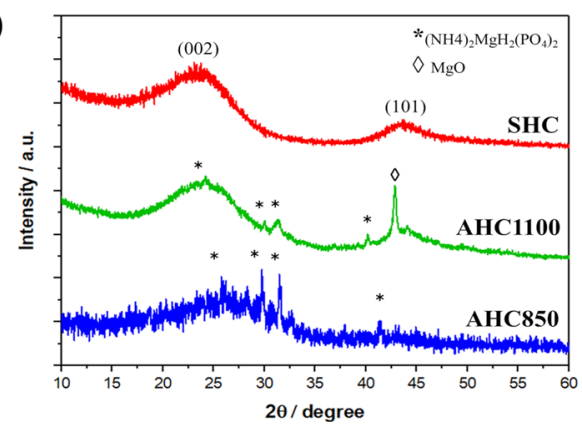


Table 1 Values of peak position relative to (002) plane, interlayer distance $\left(d_{002}\right)$, average crystallite thickness $\left(L_{\mathrm{c}}\right)$ and average number of stacked graphene layers $(N)$. The $K$ shape factor used for $L_{\mathrm{c}}$ calculation was assumed to be 0.89 , as suggested by Lu et al. [28]

\begin{tabular}{lllll}
\hline & 2Theta $(\mathrm{deg})$ & d-spacing $(\mathrm{nm})$ & Lc $(\mathrm{nm})$ & $\mathrm{N}$ \\
\hline SHC & 23.36 & 0.38 & 11.64 & 3.06 \\
AHC1100 & 24.23 & 0.37 & 12.81 & 3.49 \\
AHC850 & 26.07 & 0.34 & 6.86 & 2.01 \\
\hline
\end{tabular}

typical diffraction pattern of $\mathrm{HC}$ materials, with the two broad peaks at around $26^{\circ}$ and $44^{\circ}$ corresponding to the (002) and (101) planes, respectively. Analogously, algal pyrolyzed powder had a similar structure, but the AHC 850 clearly showed more amorphous phase content due to the much broader (002) peak. In Table 1, the parameters relative to interlayer distance $\left(\mathrm{d}_{002}\right)$, the average thickness of the order-layered nanodomains $\left(L_{\mathrm{c}}\right)$ and number of stacked graphene layers $\left(N\right.$, with $\left.N=L_{\mathrm{c}} / d_{002}\right)$ are reported. The $d_{002}$ value is $0.38 \mathrm{~nm}$ for $\mathrm{SHC}$ and $0.37 \mathrm{~nm}$ and $0.34 \mathrm{~nm}$ for AHC1100 and AHC850, respectively; values well above the $0.335 \mathrm{~nm}$ typical of graphite. The crystallite thickness was calculated by Debye-Scherrer equation, revealing similar values for SHC and AHC1100, $0.11 \mathrm{~nm}$ and $0.12 \mathrm{~nm}$, respectively, and relatively low as $0.68 \mathrm{~nm}$ for AHC 850 . This difference is reasonable considering that at higher pyrolysis temperature, partial reconstruction of graphenic domains in more short range ordered structure takes place [29]. Moreover, the presence of impurities and secondary phases was clearly detected in Chlorella vulgaris-derived $\mathrm{HC}$, as already evidenced by EDS analysis. In particular, secondary peaks can be associated to residues of minerals of magnesium and phosphate. Very similar results were observed by Meng et al. after the pyrolysis of blue-green algae, suggesting a peculiarity in pyrolysis residues composition for this kind of biowaste sources [14]. Increasing pyrolysis temperature likely promotes partial secondary phases decomposition and recrystallization that clearly results in crystalline $\mathrm{MgO}$ as evidenced by the raise of intense (200) peak at $42.9^{\circ}$. However, phosphorus, known to be commonly present in high quantity in algae, could also be present as a substitute of carbon in random site along the carbon skeleton [24]. The use of carbon-based structures doped with phosphorus as anodic active materials in both $\mathrm{Li}$ and $\mathrm{Na}$ batteries is widely reported in the literature [30-32] and their synergistic combination leads to high specific reversible capacities upon cycling and coulombic efficiency close to $100 \%$. On the other hand, $\mathrm{MgO}$ has been reported to act as templating agent in the interstices between different carbon planes, allowing the formation of a uniform porosity and facilitating the cyclic intercalation of the relatively big sodium ions and buffering the volume change accommodation upon cycling $[33,34]$.
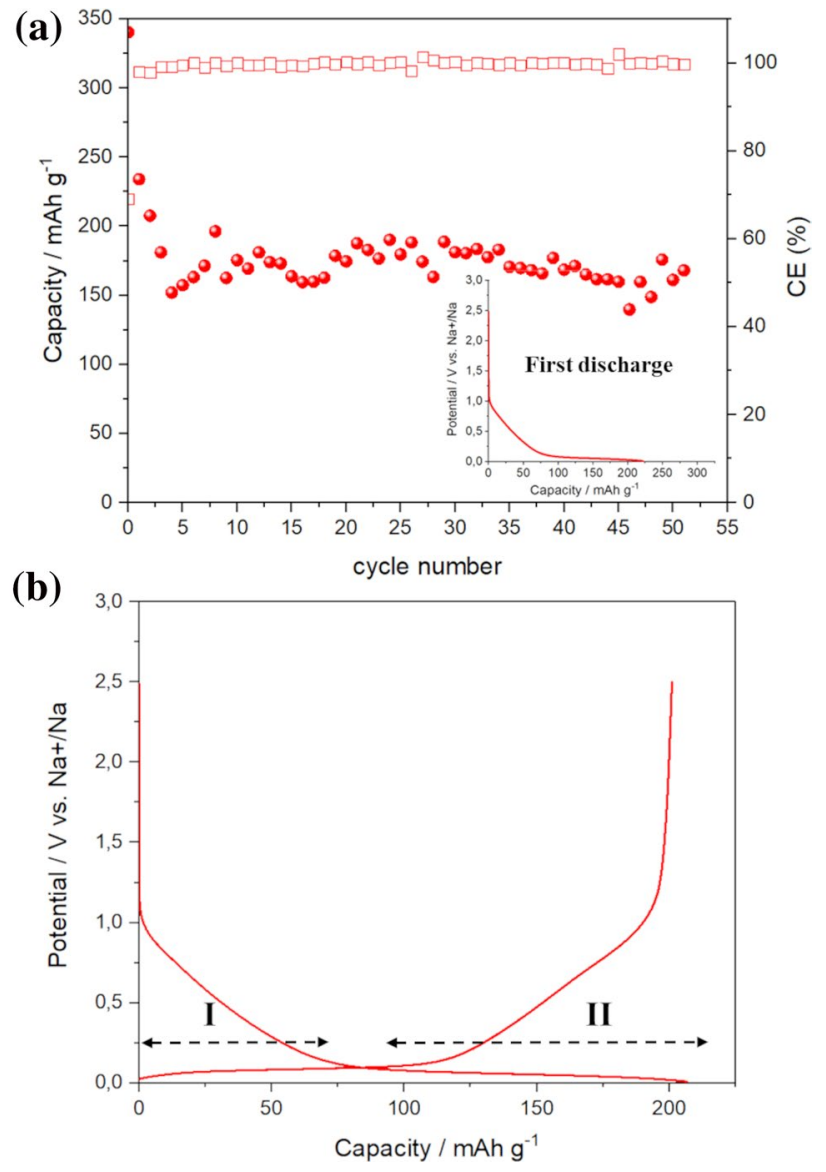

Fig. 3 a Specific capacity and coulombic efficiency for SHC electrodes casted at $100 \mu \mathrm{m}$, cycled at $25 \mathrm{~mA} \mathrm{~g}^{-1}$. First discharge profile is shown in inset figure. In (b) the 3rd charge/discharge cycle is reported, and the 2-stage discharge profile is evidenced

The SHC electrode was first investigated as benchmark. In Fig. 3a, the specific capacity and coulombic efficiency for the SHC electrode are reported. The SHC electrode cycled at $25 \mathrm{~mA} \mathrm{~g}^{-1}$ showed quite high initial discharge capacity, reaching a value of around $340 \mathrm{mAh} \mathrm{g}^{-1}$, followed by a sharp specific capacity drop in the subsequent cycles. This is usually associated with the irreversible reaction occurring at the anode/electrolyte interface leading to the solidelectrolyte interface (SEI) formation [35]. As previously reported, this thin heterogeneous layer originates from the electrochemical reduction of $\mathrm{C}=\mathrm{O}$ groups of carbonate electrolytes in the $0.5-0.4 \mathrm{~V}$ vs. $\mathrm{Na}^{+} / \mathrm{Na}$ range, resulting in both organic and inorganic byproducts as sodium ethylenedicarbonate and sodium carbonate [36, 37].

In general, SHC electrodes showed the typical 2-stage discharge profile of sodiation of $\mathrm{HC}$ materials, clearly visible in Fig. 3b. The exact nature of this behaviour is still under debate, but it is conventionally attributed to the intercalation-pore filling mechanism or the adsorption-intercalation-pore filling 
mechanism [38]. In general, the overall $\mathrm{Na}^{+}$storage reaction in $\mathrm{HC}$ can be expressed as follows:

$C_{\text {site }}+x \mathrm{Na}++x e-\rightarrow \mathrm{Nax} C_{\text {site }}$

where "site" can be defects, micropores or graphitic domain interlayers according to the distinct mechanism. The sloped Region I is due to the capacity contribution from $\mathrm{HC}$

(a)

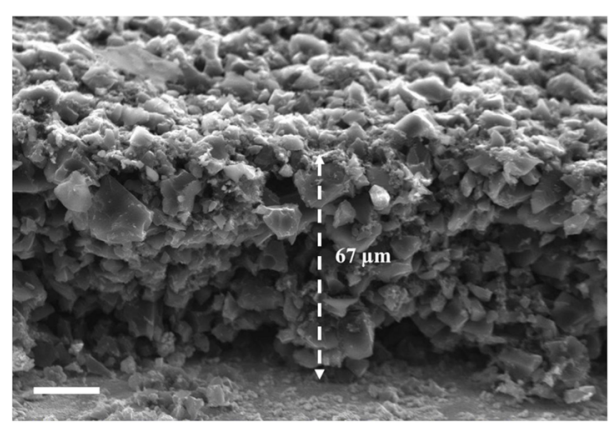

(c)

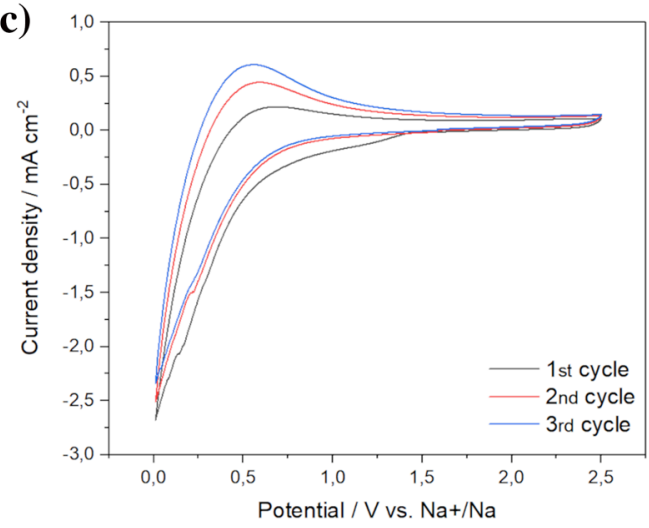

(e)

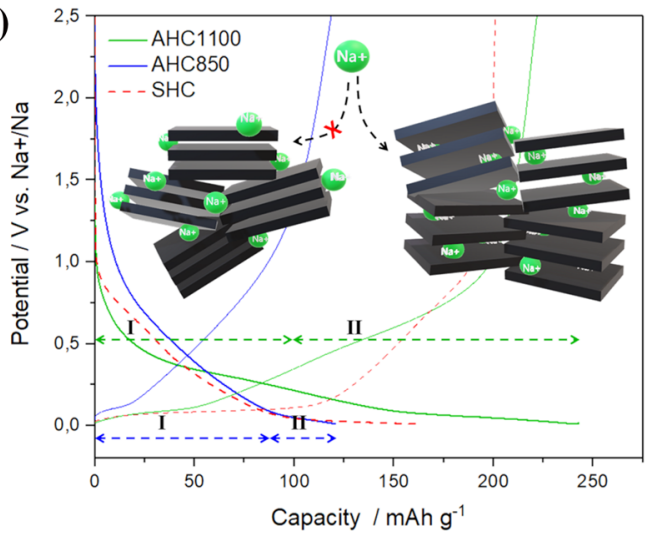

Fig. 4 a SEM image of the cross-section of the AHC850 electrode casted at $100 \mu \mathrm{m}$. As assumed, all the electrodes have similar dried thickness. Cyclic voltammetries for AHC850 (b) and AHC1100 (c) in the $2.5-0.01 \mathrm{~V}$ vs. $\mathrm{Na}+/ \mathrm{Na}$ range at $0.5 \mathrm{mV} \mathrm{s}^{-1}$. In (d) the specific capacity and CE of the AHC 850 and the first 20 cycles for AHC 1100 are reported, with first discharge profiles in inset figure. At bottom- sodiation, while the plateau-like Region II comes from the filling of nanoporosities between randomly stacked layers. According to the second mechanism, sodiation and pore filling occur in the plateau-like region, while the adsorption at defects is responsible for the sloped capacity. However, specific capacity rapidly decreased from 230 to $150 \mathrm{mAh} \mathrm{g}^{-1}$ in few cycles, but almost stabilized at around 170-160 mAh $\mathrm{g}^{-1}$ up to the 50th cycle, as an indication of a good cycling

(b)

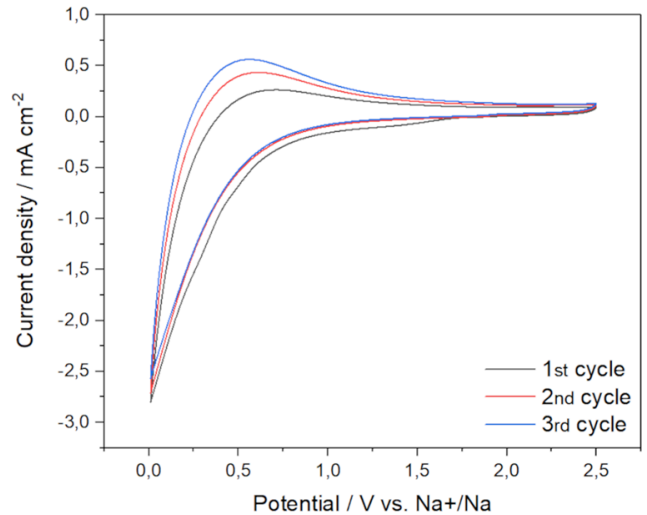

(d)

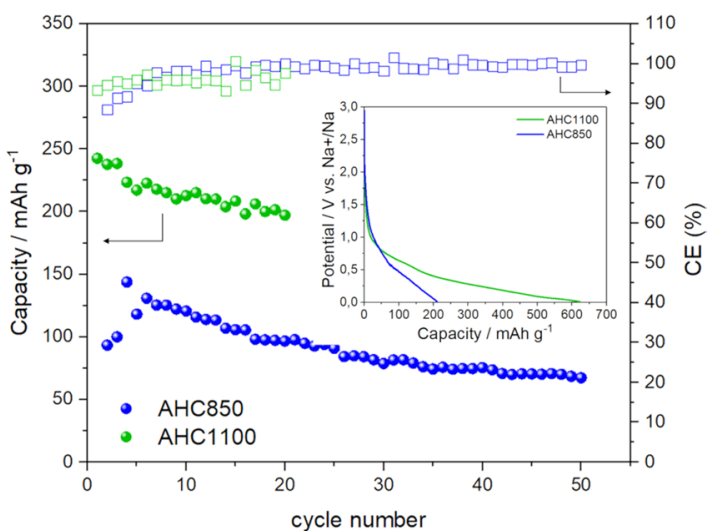

(f)

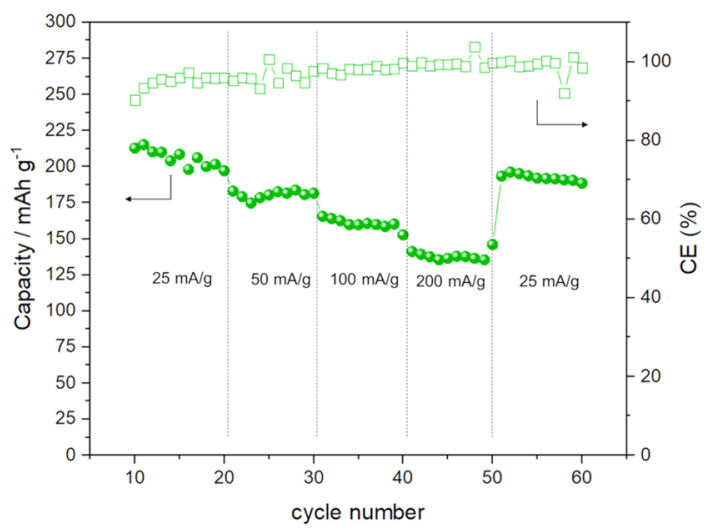

left (e) the discharge profiles of the 5th cycle are shown to highlight the different electrochemical behaviour. The inset image schematically represents the different $\mathrm{Na}^{+}$storage mechanism according to Chlorella Vulgaris pyrolysis temperature. In bottom-right image (f) the current rate test is shown and only the last initial 10 cycles at 25 $\mathrm{mAh}^{-1}$ are reported 
stability. The SEM image of Fig. 4a depicts the section of the dried AHC850 electrode casted at $100 \mu \mathrm{m}$ thickness on the copper current collector. As evident, the final thickness of the dried electrode is reduced to $\sim 70 \mu \mathrm{m}$ and the few tens $\mu \mathrm{m}$ $\mathrm{AHC}$ particles are visible and uniformly distributed. Cyclic voltammetries for both AHC 850 and AHC1100 are reported in Fig. 4b, d, showing a similar behaviour representative of the adsorption/insertion mechanism below $0.5 \mathrm{~V}$ vs. $\mathrm{Na}^{+}$/ $\mathrm{Na}$. The specific capacity and coulombic efficiency values for the AHC850 electrode are reported in Fig. 4c, along with the relative value of the first 20 cycles of AHC 1100 . The AHC850 specific capacity rapidly dropped from 220 $\mathrm{mAh} \mathrm{g}^{-1}$ of the first discharge to $91 \mathrm{mAh} \mathrm{g}^{-1}$ of second cycle. After few cycles of capacity recovery, usually associated to stabilization cycles resulting in better electrification and activation of active material, the capacity monotonically decreased up to the 50th cycle corresponding to a low value of $67 \mathrm{mAh} \mathrm{g}^{-1}$. The slow capacity fade could be due to a reduction of the redox active sites, likely caused by the cycling-induced strain on the electrode or SEI accumulation producing an occlusion of pores in the electrode matrix, de-electrification or deactivation of redox sites [36]. The AHC1100 electrode showed a remarkable improvement in capacity performance with respect to AHC850.

The high but irreversible first discharge capacity was likely associated to $\mathrm{Na}^{+}$reaction with impurities and secondary phases rather than the high surface area. Many authors reported a decrease of specific area and simultaneous expansion of nano and mesoporosity dimensions by increasing pyrolysis temperature of biological precursor in the $1000-1500{ }^{\circ} \mathrm{C}$ range [39-41]. The electrochemical behaviour was drastically improved with respect to the lowtemperature pyrolysis sample. The initial 2 nd cycle capacity value of $220 \mathrm{mAh} \mathrm{g}^{-1}$ was more than doubled with respect to AHC850 electrode and it decreased quite linearly, but very slowly in the subsequent cycles, remaining just below $200 \mathrm{mAh} \mathrm{g}^{-1}$ at the 20th cycle. The difference in electrochemical performances can be finely appreciated by considering the discharge profiles in Fig. 4d, highlighting a significant difference in the electrochemical behaviour. For the AHC850 electrode, the Region I-related capacity was by far predominant on the plateau-characteristic Region II, which is almost negligible. In accordance with previous works $[13,42]$, the transition occurs at $\sim 0.1 \mathrm{~V}$ vs. $\mathrm{Na}^{+} / \mathrm{Na}$ allowing to estimate the contribution of the intercalation/ pore filling mechanism as the $28.8 \%$ of the total capacity. This behaviour could be explained considering the low final pyrolysis temperature that resulted in a relatively thin interlayer distance, as revealed by XRD, which is not suitable for the full exploitation of the $\mathrm{Na}^{+}$intercalation contribution. Moreover, moderate pyrolysis temperature usually yields in a high specific area biochar with higher defectivity that may promote capacitive contribution [43, 44]. In summary, the minor capacity of low pyrolysis temperature derived hard carbon can be addressed precisely to the absence of the plateau contribution. As opposite, performing pyrolysis at $1100{ }^{\circ} \mathrm{C}$ resulted in $\mathrm{HC}$ material that clearly showed a broad and flat contribution in Region II, counting for the $58.9 \%$ of the total capacity. Reasonably, the increased interlayer distance allowed sodium ion intercalation between graphenic planes. Moreover, both the secondary phase pseudo-capacity, evident in the $0.5-0.2 \mathrm{~V}$ vs. $\mathrm{Na}^{+} / \mathrm{Na}$ range, and adsorption at microporosities occurring at $\mathrm{V}<0.2-0.1 \mathrm{~V}$ vs. $\mathrm{Na}^{+} /$ $\mathrm{Na}$ unlocked a further capacity contribution with respect to AHC850 electrode. The rate performances of the AHC1100 electrode were investigated by cycling it at different current density for 10 cycles each. Figure $4 \mathrm{e}$ clearly shows the excellent capacity retention and cycle stability at high current density. Capacity was reduced to only 175,160 , and 140 $\mathrm{mAh} \mathrm{g}^{-1}$ at increasing current density and these results are coherent with the AHC microstructure refinements, together with good electrical conductivity due to better graphenic layers formation at higher pyrolysis temperature. Moreover, a remarkable and almost complete capacity recovery was obtained when the initial current was again imposed, with an average specific capacity of about $200 \mathrm{mAh} \mathrm{g}^{-1}$. This value was well above the respective 50th cycle both of the AHC 850 and, in particular, SHC electrode, demonstrating that Chlorella vulgaris-derived $\mathrm{HC}$ can be a candidate for the next-generation $\mathrm{HC}$ for high-performance $\mathrm{Na}$-ion batteries. In summary, our results clearly indicate that the carbonization profile of the starting algal material has to be carried out at high temperatures, e.g. $1000{ }^{\circ} \mathrm{C}$ and above. In this way, a stable and open structure hard carbon is formed with high specific activity. Moreover, no high-MW residues are present, yielding a clean surface structure, thus preventing any hindering of the exposed surface sites.

\section{Conclusion}

In this study, the use of $\mathrm{HC}$ carbon derived from low cost and Chlorella vulgaris algal biomass has been experimentally proved as a high capacity and stable anodic active materials for Na-ion battery electrodes. The controlled pyrolysis of lab grown algae allows to obtain HC open structures suitable for $\mathrm{Na}^{+}$intercalation. The effect of pyrolysis temperature on final electrochemical performances was highlighted as crucial parameter for the development of high-performance $\mathrm{Na}$ batteries. Algae-derived HC surpasses synthetic HC electrodes in terms of both specific capacity and capacity retention upon cycling. Moreover, the advantages derived from using this biomass material are, therefore, not only in terms of improved electrochemical performances, but in 
lower production costs and reduced environmental impact with respect to synthetic materials.

Acknowledgements Fondazione Banca Monte di Lombardia - "Abissi" project is gratefully acknowledged for its financial support.

Funding Open access funding provided by Politecnico di Milano within the CRUI-CARE Agreement.

Open Access This article is licensed under a Creative Commons Attribution 4.0 International License, which permits use, sharing, adaptation, distribution and reproduction in any medium or format, as long as you give appropriate credit to the original author(s) and the source, provide a link to the Creative Commons licence, and indicate if changes were made. The images or other third party material in this article are included in the article's Creative Commons licence, unless indicated otherwise in a credit line to the material. If material is not included in the article's Creative Commons licence and your intended use is not permitted by statutory regulation or exceeds the permitted use, you will need to obtain permission directly from the copyright holder. To view a copy of this licence, visit http://creativecommons.org/licenses/by/4.0/.

\section{References}

1. Van Noorden R (2014) The rechargeable revolution: a better battery. Nature News 507:26. https://doi.org/10.1038/507026a

2. Yabuuchi N, Kubota K, Dahbi M, Komaba S (2014) Research development on sodium-ion batteries. Chem Rev 114:1163611682. https://doi.org/10.1021/cr500192f

3. Chang G, Zhao Y, Dong L et al (2020) A review of phosphorus and phosphides as anode materials for advanced sodium-ion batteries. J Mater Chem A 8:4996-5048. https://doi.org/10.1039/ C9TA12169B

4. Lao M, Zhang Y, Luo W et al (2017) Alloy-based anode materials toward advanced sodium-ion batteries. Adv Mater 29:1700622. https://doi.org/10.1002/adma.201700622

5. Tomboc GM, Wang Y, Wang H et al (2021) Sn-based metal oxides and sulfides anode materials for Na ion battery. Energy Storage Mater. 39:21-44. https://doi.org/10.1016/j.ensm.2021.04.009

6. Lei Y-J, Yan Z-C, Lai W-H et al (2020) Tailoring MXene-based materials for sodium-ion storage: synthesis, mechanisms, and applications. Electrochem Energ Rev 3:766-792. https://doi.org/ 10.1007/s41918-020-00079-y

7. Irisarri E, Ponrouch A, Palacin MR (2015) Review-hard carbon negative electrode materials for sodium-ion batteries. J Electrochem Soc 162:A2476. https://doi.org/10.1149/2.0091514jes

8. Dahn JR, Xing W, Gao Y (1997) The "falling cards model" for the structure of microporous carbons. Carbon 35:825-830. https://doi. org/10.1016/S0008-6223(97)00037-7

9. Yu P, Tang W, Wu F-F et al (2020) Recent progress in plantderived hard carbon anode materials for sodium-ion batteries: a review. Rare Met 39:1019-1033. https://doi.org/10.1007/ s12598-020-01443-Z

10. Zhu J, Roscow J, Chandrasekaran S et al (2020) Biomass-derived carbons for sodium-ion batteries and sodium-ion capacitors. ChemSusChem 13:1275-1295. https://doi.org/10.1002/cssc. 201902685

11. Wang N, Liu Q, Sun B et al (2018) N-doped catalytic graphitized hard carbon for high-performance lithium/sodium-ion batteries. Sci Rep 8:9934. https://doi.org/10.1038/s41598-018-28310-3

12. Wang X, Wang S, Shen K et al (2020) Phosphorus-doped porous hollow carbon nanorods for high-performance sodium-based dual-ion batteries. J Mater Chem A 8:4007-4016. https://doi.org/ 10.1039/C9TA11246D

13. Alvin S, Chandra C, Kim J (2020) Extended plateau capacity of phosphorus-doped hard carbon used as an anode in $\mathrm{Na}$ - and $\mathrm{K}$-ion batteries. Chem Eng J 391:123576. https://doi.org/10.1016/j.cej. 2019.123576

14. Meng X, Savage PE, Deng D (2015) Trash to treasure: from harmful algal blooms to high-performance electrodes for sodium-ion batteries. Environ Sci Technol 49:12543-12550. https://doi.org/ 10.1021/acs.est.5b03882

15. Dou X, Hasa I, Saurel D, Jauregui M, Buchholz D, Rojo T, Passerini S (2018) Impact of the acid treatment on lignocellulosic biomass hard carbon for sodium-ion battery anodes. ChemSusChem 11:3276-3285. https://doi.org/10.1002/cssc.201801148

16. Wu L, Buchholz D, Vaalma C et al (2016) Apple-biowastederived hard carbon as a powerful anode material for na-ion batteries. ChemElectroChem 3:292-298. https://doi.org/10. 1002/celc. 201500437

17. Lotfabad EM, Ding J, Cui K et al (2014) High-density sodium and lithium ion battery anodes from banana peels. ACS Nano 8:7115-7129. https://doi.org/10.1021/nn502045y

18. Lv W, Wen F, Xiang J et al (2015) Peanut shell derived hard carbon as ultralong cycling anodes for lithium and sodium batteries. Electrochim Acta 176:533-541. https://doi.org/10.1016/j. electacta.2015.07.059

19. Zhu Y, Chen M, Li Q et al (2018) A porous biomass-derived anode for high-performance sodium-ion batteries. Carbon 129:695-701. https://doi.org/10.1016/j.carbon.2017.12.103

20. Gao C, Wang Q, Luo S et al (2019) High performance potassium-ion battery anode based on biomorphic N-doped carbon derived from walnut septum. J Power Sources 415:165-171. https://doi.org/10.1016/j.jpowsour.2019.01.073

21. Han J, Lee K, Choi MS et al (2019) Chlorella-derived activated carbon with hierarchical pore structure for energy storage materials and adsorbents. Carbon Lett 29:167-175. https://doi.org/ 10.1007/s42823-019-00018-y

22. Liberale F, Dossi C, Bettinetti R et al (2017) Algae derived electrodes for rechargeable Na-ion batteries: materials characterization and electrochemical performances. ECS Trans 80:349. https://doi.org/10.1149/08010.0349ecst

23. Binda G, Spanu D, Bettinetti R et al (2020) Comprehensive comparison of microalgae-derived biochar from different feedstocks: a prospective study for future environmental applications. Algal Res 52:102103. https://doi.org/10.1016/j.algal. 2020.102103

24. Bach Q-V, Chen W-H (2017) Pyrolysis characteristics and kinetics of microalgae via thermogravimetric analysis (TGA): a stateof-the-art review. Biores Technol 246:88-100. https://doi.org/10. 1016/j.biortech.2017.06.087

25. Kebelmann K, Hornung A, Karsten U, Griffiths G (2013) Intermediate pyrolysis and product identification by TGA and Py-GC/ MS of green microalgae and their extracted protein and lipid components. Biomass Bioenerg 49:38-48. https://doi.org/10.1016/j. biombioe.2012.12.006

26. Gong X, Zhang B, Zhang Y et al (2014) Investigation on pyrolysis of low lipid microalgae Chlorella vulgaris and Dunaliella salina. Energy Fuels 28:95-103. https://doi.org/10.1021/ef401500z

27. Demirbas A (2004) Effects of temperature and particle size on bio-char yield from pyrolysis of agricultural residues. J Anal Appl Pyrol 72:243-248. https://doi.org/10.1016/j.jaap.2004.07.003

28. Lu H, Ai F, Jia Y et al (2018) Exploring sodium-ion storage mechanism in hard carbons with different microstructure prepared by ball-milling method. Small 14:1802694. https://doi.org/10.1002/ smll.201802694

29. Marsh H, Rodriguez-Reinoso F (2006) Activated carbon, 1st edn. Elsevier Science, New York 
30. Ding J, Zhang Y, Huang Y et al (2021) Sulfur and phosphorus co-doped hard carbon derived from oak seeds enabled reversible sodium spheres filling and plating for ultra-stable sodium storage. J Alloy Compd 851:156791. https://doi.org/10.1016/j.jallc om.2020.156791

31. Li Z, Ma L, Surta TW et al (2016) High capacity of hard carbon anode in Na-ion batteries unlocked by POx doping. ACS Energy Lett 1:395-401. https://doi.org/10.1021/acsenergylett.6b00172

32. Li Y, Wang Z, Li L et al (2016) Preparation of nitrogen- and phosphorous co-doped carbon microspheres and their superior performance as anode in sodium-ion batteries. Carbon 99:556-563. https://doi.org/10.1016/j.carbon.2015.12.066

33. Konno H, Onishi H, Yoshizawa N, Azumi K (2010) MgO-templated nitrogen-containing carbons derived from different organic compounds for capacitor electrodes. J Power Sources 195:667673. https://doi.org/10.1016/j.jpowsour.2009.07.039

34. Zhu C, Akiyama T (2016) Cotton derived porous carbon via an $\mathrm{MgO}$ template method for high performance lithium ion battery anodes. Green Chem 18:2106-2114. https://doi.org/10.1039/ C5GC02397A

35. Chen L, Fiore M, Wang JE et al (2018) Readiness level of sodiumion battery technology: a materials review. Adv. Sustain. Syst. 2:1700153. https://doi.org/10.1002/adsu.201700153

36. Carboni M, Manzi J, Armstrong AR et al (2019) Analysis of the solid electrolyte interphase on hard carbon electrodes in sodiumion batteries. ChemElectroChem 6:1745-1753. https://doi.org/10. 1002/celc.201801621

37. Pan Y, Zhang Y, Parimalam BS et al (2017) Investigation of the solid electrolyte interphase on hard carbon electrode for sodium ion batteries. J Electroanal Chem 799:181-186. https://doi.org/ 10.1016/j.jelechem.2017.06.002

38. Dou X, Hasa I, Saurel D et al (2019) Hard carbons for sodium-ion batteries: structure, analysis, sustainability, and electrochemistry.
Mater Today 23:87-104. https://doi.org/10.1016/j.mattod.2018. 12.040

39. Izanzar I, Dahbi M, Kiso M et al (2018) Hard carbons issued from date palm as efficient anode materials for sodium-ion batteries. Carbon 137:165-173. https://doi.org/10.1016/j.carbon.2018.05. 032

40. Dahbi M, Kiso M, Kubota K et al (2017) Synthesis of hard carbon from argan shells for Na-ion batteries. J Mater Chem A 5:99179928. https://doi.org/10.1039/C7TA01394A

41. Cao B, Liu H, Xu B et al (2016) Mesoporous soft carbon as an anode material for sodium ion batteries with superior rate and cycling performance. J Mater Chem A 4:6472-6478. https://doi. org/10.1039/C6TA00950F

42. Alvin S, Yoon D, Chandra C et al (2019) Revealing sodium ion storage mechanism in hard carbon. Carbon 145:67-81. https://doi. org/10.1016/j.carbon.2018.12.112

43. Qin C, Wang H, Yuan X et al (2020) Understanding structure-performance correlation of biochar materials in environmental remediation and electrochemical devices. Chem Eng J 382:122977. https://doi.org/10.1016/j.cej.2019.122977

44. Matei Ghimbeu C, Górka J, Simone V et al (2018) Insights on the $\mathrm{Na}+$ ion storage mechanism in hard carbon: discrimination between the porosity, surface functional groups and defects. Nano Energy 44:327-335. https://doi.org/10.1016/j.nanoen.2017.12.013

Publisher's Note Springer Nature remains neutral with regard to jurisdictional claims in published maps and institutional affiliations. 